\title{
Prevalence of dental caries and its association with body mass index among school-age children in Shenzhen, China
}

\author{
Yi-hong Cheng ${ }^{1 \dagger}, \mathrm{Yi} \mathrm{Liao}^{2 \dagger}$, Ding-yan Chen ${ }^{2}$, Yun Wang ${ }^{2}$ and Yu Wu ${ }^{2^{*}}$ (D)
}

\begin{abstract}
Background: Dental caries and overweight/obesity are health problems with shared risk factors, but the relationships between caries and BMI need to be further explored. The objective was to evaluate the current status of dental caries and the association between dental caries and Body Mass Index (BMI) among primary and secondary school students in Shenzhen, China, during the 2016-2017 academic year.

Methods: A population-based, cross-sectional study that enrolled a total of 1,196,004 students was conducted in Shenzhen. Physical and dental examinations were given to all primary and secondary school students by certified physicians and dentists following the national specification for student health examinations, and dental caries was diagnosed using WHO criteria. Descriptive analysis was applied to assess current oral health status and a multifactorial, logistic regression model was employed to evaluate the relationship between dental caries and obesity.
\end{abstract}

Results: A total of 1,196,004 students participated in the census. Mean age of the participants was 10.3 years, ranging from 6 to 20 years. The prevalence of dental caries was $41.15 \%$ in the present study, which was higher among girls $(42.88 \%)$ than that in boys (39.77\%) with a $p$-value of $<0.001$. Students in public schools showed a significantly lower $(p<0.001)$ caries prevalence $(37.36 \%)$ compared with those in private schools $(47.96 \%)$. The caries restoration rate of students in Shenzhen was only $10.30 \%$, which means only one out of ten students with caries received restorations. The mean dmft and DMFT scores were 0.97 and 0.33, respectively. More girls (10.96\%) had their teeth filled than boys (9.78\%). The restoration rate was higher $(p<0.001)$ in public schools $(11.73 \%)$ than in private ones $(8.35 \%)$. Children who were overweight or obese had a lower risk of experiencing caries compared to those who were within a normal weight $(O R=0.74 / 0.64)$. Caries was inversely associated with $B M l$ among primary and secondary school students in Shenzhen.

Conclusions: The prevalence of dental caries among primary and secondary school children was found to be related to sex, type of schools, region, and BMI. Further studies and more government support are required to confirm the findings of this study and to address current oral health problems.

\section{Introduction}

Dental caries is one of the most prevalent chronic diseases among children [1]. According to the China's Fourth National Oral Health Epidemiological Survey of 2017 $[2,3], 70.1 \%$ of 5 -year-old children had primary dental caries and $34.5 \%$ of 12 -year-old students had experienced dental caries in their permanent teeth [4]. Previous surveys conducted in other locations in China [5-7] have indicated

\footnotetext{
* Correspondence: wuyu84@foxmail.com

Yi-hong Cheng and Yi Liao are Joint first authors.

${ }^{2}$ Shenzhen Center for Disease Control and Prevention, Shenzhen, China

Full list of author information is available at the end of the article
}

high caries rates and low restorative rates among primary and secondary school students. Unhealthy diet, such as high calorie food, has been reported as a significant determinant of the increased prevalence of dental caries [8]. In addition, dietary factors have also contributed to the rising prevalence of childhood overweight/obesity worldwide in past decades $[9,10]$. Given the shared risk factors between dental caries and overweight/obesity in childhood, studies examining the relationship between these two health problems have been conducted. However, results of previous studies have so far been inconsistent. Some authors have

(c) The Author(s). 2019 Open Access This article is distributed under the terms of the Creative Commons Attribution 4.0 International License (http://creativecommons.org/licenses/by/4.0/), which permits unrestricted use, distribution, and 
found a positive association [11, 12], while others reported no relationship $[13,14]$ or a negative one [15].

Moreover, few studies on estimating current dental caries status and the relationship between caries and BMI have been conducted in Shenzhen. Shenzhen is the largest immigrant city in China, with immigrants accounting for more than $70 \%$ of the population [16]. Due to diversified customs and rapid economic growth, the lifestyle of Shenzhen's population has changed dramatically. Given that dental caries, which can affect the growth and development of school-age children [17], and is largely preventable, an updated study on evaluating the current status and identifying associated factors in Shenzhen is warranted.

Therefore, in order to estimate the current status, to compare potential disparities between regions of dental caries, and to determinate whether there is any association between dental caries and BMI among primary and secondary school children in Shenzhen, a population-based survey of students' health was conducted. Our results should increase the understanding of dental health in Shenzhen school children and provides scientific evidence for policy and legislation development.

\section{Methods}

\section{Sample enrollment}

During the 2016-2017 academic year, a populationbased census of students' health and corporeity was conducted among all the primary and secondary school students by the Shenzhen government. This census covered both public and private schools, including a total of 1,196,004 students.

\section{Data collection}

Dental and physical examinations were given to students by physicians and dentists trained with the national criteria (Technical Specification for Student Health Examination, GB-T-26343 2010 criteria) [18]. A flat mouth mirror and CPI probe were used for the dental examination. One-to-one dental caries detection was performed for each child, and gingivitis, tartar, and periodontal depth were recorded. Caries was diagnosed according to WHO criteria and caries experience was measured as the DMFT (number of decayed, missing, and filled permanent teeth) while the $\mathrm{dmft}$ was used for primary teeth. The presence of caries was diagnosed if $\mathrm{dmft} / \mathrm{DMFT}>0$.

BMI, as used in this study, was calculated as weight $(\mathrm{kg})$ divided by squared height $\left(\mathrm{m}^{2}\right)$. We applied cut-off criteria recommended by the Group of China Obesity Task Force and used a population-based reference curve obtained from the 2000 national physical fitness and health surveillance data [19]. Subjects were categorized as moderate/severe malnutrition, mild malnutrition, normal weight, overweight, and obese according to cutoff values stratified by sex and age [19]. Overweight was defined as between 85 and $95 \%$ on the reference curve, and obese as higher or equivalent to $95 \%$.

Demographic information (age, sex, residence, type of school) was obtained from the Shenzhen students' health surveillance system. This study used secondary data collected from students' health census in Shenzhen. All the data has been anonymised, therefore ethical approval was not required to our study.

\section{Statistical analysis}

Qualitative data is presented as frequency and proportion. The prevalence of dental caries, mean $\mathrm{dmft} /$ DMFT scores, and caries restoration rates were mapped according to districts. Mean $\mathrm{dmft} / \mathrm{DMFT}$ is the average score of caries status in both primary and permanent teeth, and caries restoration rate is the proportion of students who received restoration treatment among students with caries. Chi-square tests were conducted to compare the differences in caries prevalence and restoration rates by socioeconomic groups, such as age and type of school. Analysis of Variance (ANOVA) was applied to compare the mean $\mathrm{dmft} / \mathrm{DMFT}$ scores by socioeconomic groups. A Multifactorial logistical regression model was applied to estimate the association between dental caries prevalence and BMI. District, sex, age group, and type of school were adjusted in this model. A $p$-value of less than 0.05 was considered statistically significant. Statistical analysis was performed using SAS 9.2 software.

\section{Results}

A total of $1,196,004$ students, including 665,728 boys (55.66\%) and 530,276 girls (44.34\%) participated in this survey. The overall prevalence of dental caries was $41.15 \%$ (Table 1 ), with a higher prevalence among girls than boys $(p<0.01)$. Age was significantly inversely associated with caries. Average restoration rates in these students remained relatively low (10.30\%) compared with the high caries prevalence.

Dental caries status has been explored by administrative districts and types of school (Fig. 1, Table 1). Significant differences in caries status were found across districts $(p<0.001)$. The Longhua district showed the highest caries prevalence $(57.83 \%)$, followed by the Dapeng new district (52.76\%). The lowest caries prevalence and mean $\mathrm{dmft} / \mathrm{DMFT}$ score were found in the Futian district. The Longgang district showed the highest restoration rates $(27.67 \%)$, while only $0.17 \%$ of children with caries in the Pingshan district had their cavities restored. Students from public schools showed lower prevalence of caries and mean $\mathrm{dmft} / \mathrm{DMFT}$ 


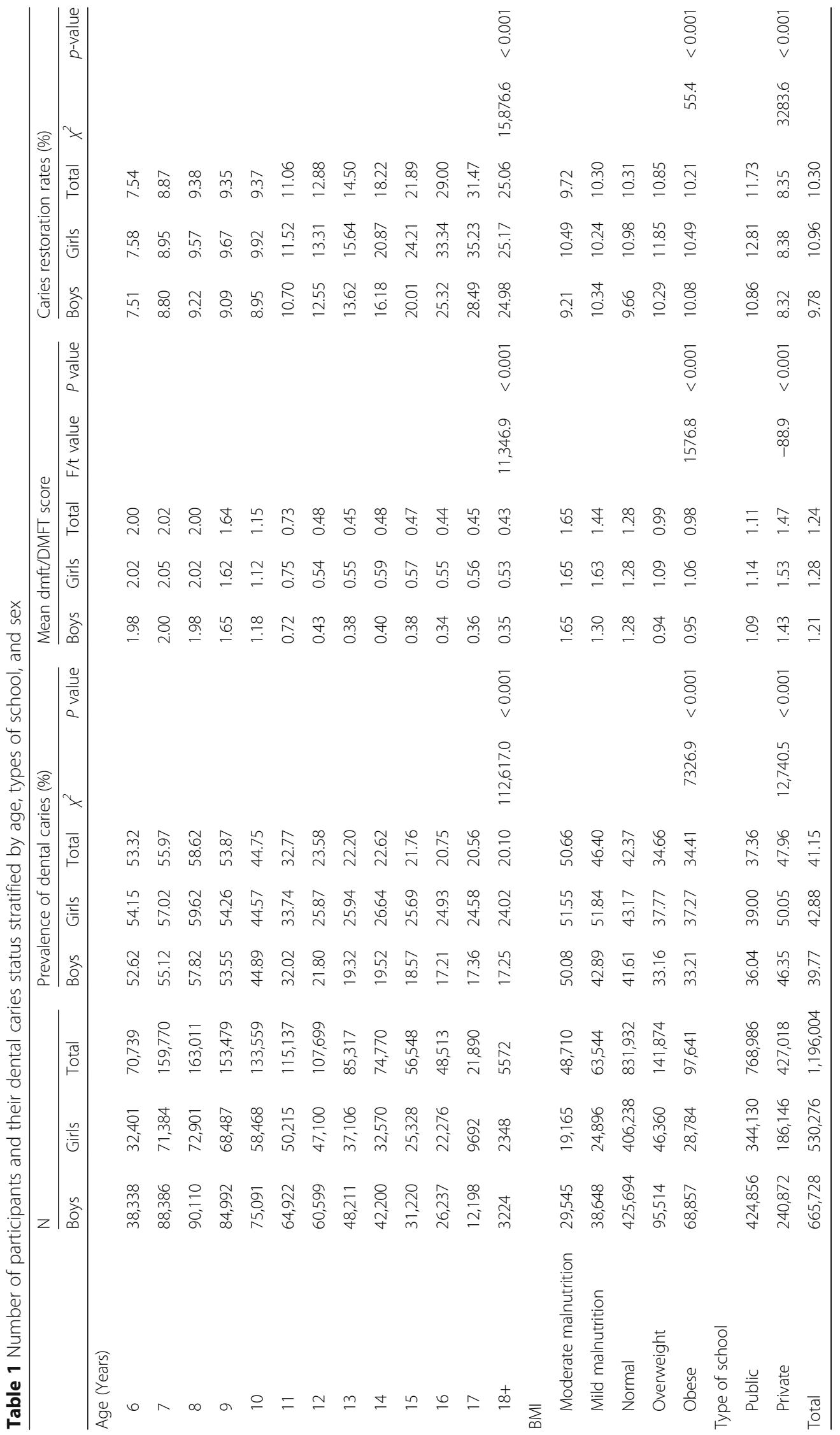




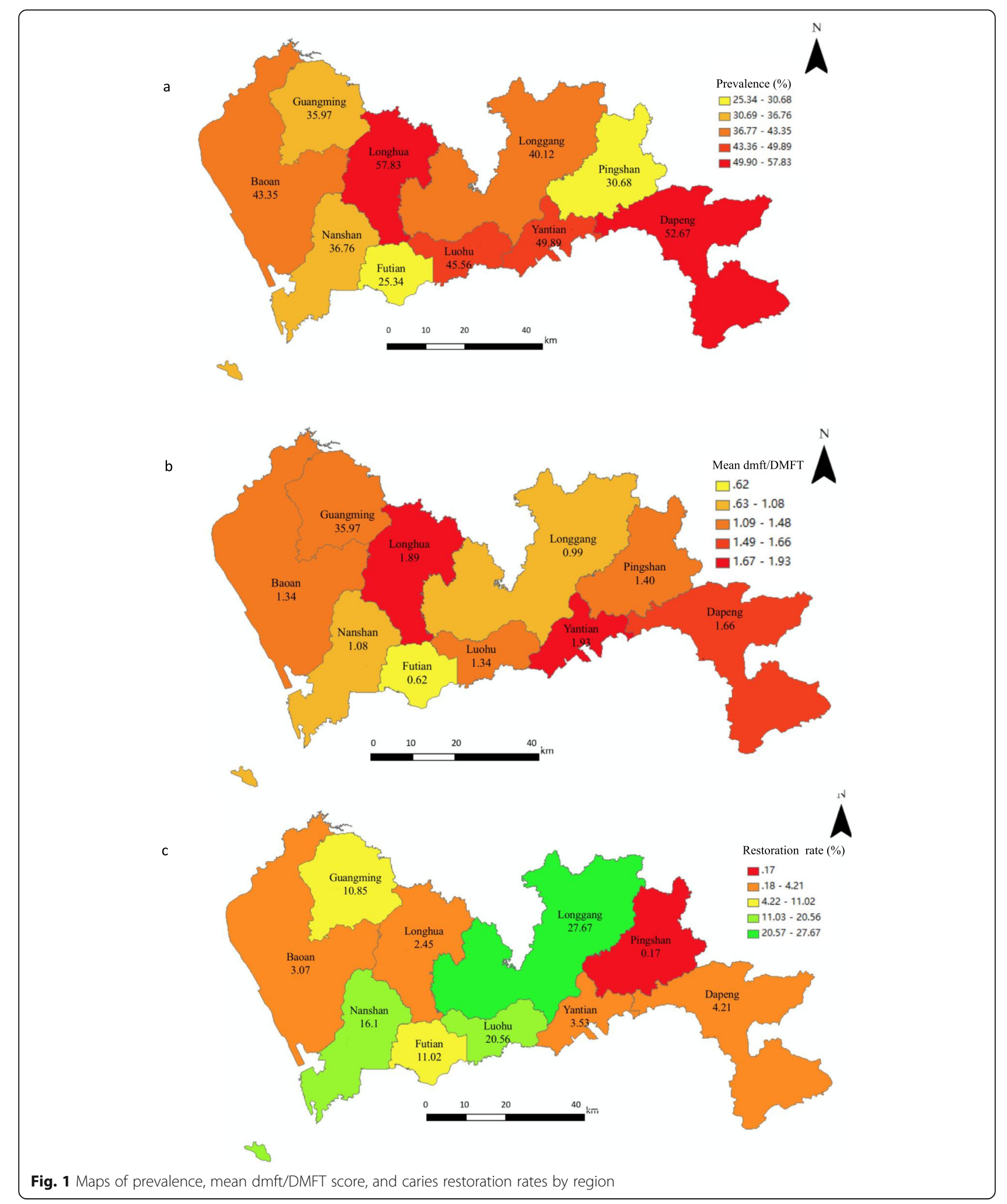

scores as well as higher caries restoration rates than those in private schools (Table 1).

As listed in Table 2, the overall prevalence of primary teeth with caries was $27.14 \%$, with a higher prevalence among girls (27.32\%) than boys (26.99\%). With increasing age, the prevalence of caries in primary teeth decreased and the prevalence of caries in permanent teeth increased. The highest caries 
Table 2 Dental caries status of primary teeth and permanent teeth

\begin{tabular}{|c|c|c|c|c|c|c|c|}
\hline \multirow[t]{2}{*}{ Variables } & \multirow[t]{2}{*}{$\mathrm{N}$} & \multicolumn{3}{|l|}{ Primary teeth } & \multicolumn{3}{|l|}{ Permanent teeth } \\
\hline & & $\begin{array}{l}\text { Prevalence of dental } \\
\text { caries (\%) }\end{array}$ & $\begin{array}{l}\text { Mean dmft } \\
\text { score }\end{array}$ & $\begin{array}{l}\text { Caries restoration } \\
\text { rates (\%) }\end{array}$ & $\begin{array}{l}\text { Prevalence of dental } \\
\text { caries (\%) }\end{array}$ & $\begin{array}{l}\text { Mean DMFT } \\
\text { score }\end{array}$ & $\begin{array}{l}\text { Caries restoration } \\
\text { rates }(\%)\end{array}$ \\
\hline \multicolumn{8}{|l|}{ Sex } \\
\hline Boys & 665,728 & 26.99 & 0.97 & 9.67 & 12.17 & 0.29 & 10.14 \\
\hline Girls & 530,276 & 27.32 & 0.96 & 10.08 & 15.44 & 0.37 & 13.23 \\
\hline \multicolumn{8}{|c|}{ Age (Year) } \\
\hline 6 & 70,739 & 45.97 & 1.92 & 8.08 & 6.18 & 0.20 & 2.41 \\
\hline 7 & 159,770 & 48.07 & 1.91 & 9.29 & 6.85 & 0.20 & 4.51 \\
\hline 8 & 163,011 & 49.13 & 1.83 & 9.76 & 9.56 & 0.25 & 6.50 \\
\hline 9 & 153,479 & 42.44 & 1.39 & 10.14 & 12.49 & 0.31 & 5.68 \\
\hline 10 & 133,559 & 30.13 & 0.84 & 10.69 & 15.40 & 0.36 & 6.22 \\
\hline 11 & 115,137 & 16.41 & 0.39 & 13.75 & 16.59 & 0.37 & 8.22 \\
\hline 12 & 107,699 & 6.40 & 0.13 & 17.24 & 16.34 & 0.36 & 11.35 \\
\hline 13 & 85,317 & 2.18 & 0.04 & 15.29 & 18.58 & 0.42 & 14.63 \\
\hline 14 & 74,770 & 1.21 & 0.02 & 12.03 & 19.81 & 0.46 & 19.02 \\
\hline 15 & 56,548 & 1.00 & 0.02 & 9.37 & 19.17 & 0.45 & 22.92 \\
\hline 16 & 48,513 & 0.92 & 0.02 & 6.63 & 18.57 & 0.42 & 30.90 \\
\hline 17 & 21,890 & 0.82 & 0.02 & 3.99 & 18.47 & 0.44 & 33.32 \\
\hline $18+$ & 5572 & 0.34 & 0.02 & 2.11 & 17.98 & 0.41 & 26.01 \\
\hline Total & $\begin{array}{l}1,196 \\
004\end{array}$ & 27.14 & 0.97 & 9.85 & 13.62 & 0.33 & 11.72 \\
\hline
\end{tabular}

restoration rate was observed in the 12-year-old age group (17.24\%) for primary teeth and in the 17-yearold age group (33.32\%) for permanent teeth.

According to the results of multifactorial logistical regression model (Table 3), the prevalence of dental caries among primary and secondary school children was found to be related to sex, type of schools, region, and BMI. Boys were less likely to have caries than girls $(\mathrm{OR}=$ 0.90), and students from private school had higher risk of experiencing dental caries compared to those from public school $(\mathrm{OR}=1.23)$. Based on BMI criteria in China, $70.28 \%$ of students were categorized as having normal weight, and about $20.23 \%$ were overweight or obese. The association between caries and BMI is demonstrated in Table 3, after adjusting the other demographic variables. Caries were more likely observed among children with malnutrition, and the difference was statistically significant $(p<0.001)$. Children who were overweight or obese had a lower risk of experiencing caries compared to those who were within a normal weight $(\mathrm{OR}=0.74 / 0.64)$, while students with moderate/ mild malnutrition had a higher risk (1.19/1.17). Also, there was a significantly higher mean dmft/DMFT score among students with low BMI compared with those who were overweight or obese $(\mathrm{p}<0.001)$ (Fig. 2). No significant difference in caries restoration rates was observed across BMI groups.

\section{Discussion}

This large population-based study found that the average prevalence of dental caries was $41.15 \%$; the mean $\mathrm{dmft}$ / DMFT score and the overall caries restoration rate were 1.24 and $10.32 \%$, respectively. The prevalence of caries was higher in primary teeth. Caries was more frequently observed among girls. Disparities in oral health conditions were found across administrative regions and type of school. Moreover, an inverse association between caries and BMI was demonstrated. Children with malnutrition were more likely to develop dental caries than those with normal weight or high BMI.

Compared with the results from the Third National Oral Health Epidemiologic Survey in 2005 [20], prevalence of caries has decreased in the recent decade, indicating an achievement in managing oral health problems. However, the prevalence of caries in some age groups remained above the target of having more than half of children free from caries, recommended by WHO and Federation of Dentistry International [21].

The prevalence of caries in primary and permanent teeth were slightly lower than that obtained from the national survey in the same year (70.1 and 34.5\%, respectively). One possible explanation is that samples in this study were collected only in Shenzhen city, which has a higher socioeconomic level and a better education standard than other cities. 
Table 3 Results of multifactorial logistical regression model

\begin{tabular}{|c|c|c|c|c|}
\hline \multirow{2}{*}{$\frac{\text { Variables }}{\text { BMI }}$} & \multirow[t]{2}{*}{ OR } & \multicolumn{2}{|c|}{$95 \% \mathrm{Cl}$} & \multirow[t]{2}{*}{$P$} \\
\hline & & & & \\
\hline Normal & 1 & & & \\
\hline Moderate malnutrition & 1.19 & 1.17 & 1.22 & $<0.001$ \\
\hline Mild malnutrition & 1.17 & 1.15 & 1.19 & $<0.001$ \\
\hline Overweight & 0.74 & 0.73 & 0.75 & $<0.001$ \\
\hline Obese & 0.64 & 0.63 & 0.65 & $<0.001$ \\
\hline \multicolumn{5}{|l|}{ District } \\
\hline Futian & 1 & & & \\
\hline Baoan & 2.00 & 1.97 & 2.04 & 0.888 \\
\hline Dapeng & 3.23 & 3.10 & 3.36 & $<0.001$ \\
\hline Guangming & 1.42 & 1.39 & 1.45 & $<0.001$ \\
\hline Longgang & 1.81 & 1.78 & 1.83 & $<0.001$ \\
\hline Longhua & 3.44 & 3.38 & 3.51 & $<0.001$ \\
\hline Luohu & 2.53 & 2.48 & 2.50 & $<0.001$ \\
\hline Nanshan & 1.68 & 1.65 & 1.71 & $<0.001$ \\
\hline Pingshan & 1.12 & 1.10 & 1.16 & $<0.001$ \\
\hline Yantian & 3.80 & 3.69 & 3.93 & $<0.001$ \\
\hline \multicolumn{5}{|l|}{ Sex } \\
\hline Girl & 1 & & & \\
\hline Boy & 0.90 & 0.89 & 0.91 & $<0.001$ \\
\hline \multicolumn{5}{|l|}{ Age } \\
\hline $6-8$ & 1 & & & \\
\hline $9-11$ & 0.62 & 0.61 & 0.62 & $<0.001$ \\
\hline $12-14$ & 0.23 & 0.22 & 0.23 & $<0.001$ \\
\hline $15-17$ & 0.21 & 0.21 & 0.22 & $<0.001$ \\
\hline$\geq 18$ & 0.26 & 0.25 & 0.28 & $<0.001$ \\
\hline \multicolumn{5}{|l|}{ Type of school } \\
\hline Public & 1 & & & \\
\hline Private & 1.23 & 1.22 & 1.24 & $<0.001$ \\
\hline
\end{tabular}

Compared with the prevalence of dental caries in other developed [17] and developing [22-24] countries, the findings in this survey indicated a lower prevalence. On the other hand, a high prevalence of primary caries was observed in the study population, affecting more than half the participants younger than 10 years. In addition, the general caries restoration rates of primary and permanent teeth were significantly lower than the average level in developed countries. Caries restoration rate is the proportion of students who received cavity restoration treatment among students with diagnosed caries. The restoration rate of primary teeth among 6-year-old children in Japan was 84\% [25]. More than $90 \%$ of children in Australia had their permanent teeth caries restorated [26]. Only $10.30 \%$ of students with caries received restorative treatment in our study population, which highlights the necessity of health education on encourage regular oral health check-ups and treatment among students in Shenzhen. Moreover, the high prevalence and low restorative rate of primary teeth partly reflects parents' general attitude toward caries protection: Since the primary teeth will be replaced with the permanent teeth, it is not necessary to protect or restore primary teeth caries [27]. According to a previous study [28], caries and missing primary teeth are major causes of permanent teeth caries. Therefore, effective measures to improve the health of primary teeth such as education programs and free dental consultation clinics are warranted.

Sex differences in dental caries and restorative rates were identified in agreement with other studies in China $[7,29]$. The following reasons may contribute to these association: firstly, girls are more fond of sweets and snacks [30]; secondly, the development of teeth regularly appeared earlier among girls [31].

Maps above show regional disparities in students' oral health status. Districts located centrally (Futian, Luohu, Longgangand Nanshan) had a generally lower prevalence and higher restoration rates of dental caries than other areas. According to one recent report [32], the four districts mentioned above ranked high in relation to gross domestic product (GDP) increase in 2017. Since management of students' health, including oral health, was administrated at district level in Shenzhen, a higher regional GDP increase was possibly associated with higher family socioeconomic levels and better government financial support.

Additionally, public school students in Shenzhen showed a higher oral health status in our study. Gerdin's group reported a decrease in caries prevalence with better socioeconomic status in all age groups [33], which may explain the disparities across districts and type of school. Nevertheless, we used data collected from the Shenzhen students' health surveillance system. Because detailed information on students' family wealth was not applicable, we could not conclude that disparities between public and private schools were related to students' socioeconomic status. Further study may be necessary to identify the socioeconomic factors associated with school disparities and to enhance awareness of dental health among children in private schools.

The increasing prevalence of obesity in children has been linked to the consumption of a sugar-rich diet, according to a longitudinal study [34], and diet was also associated with caries experience [13]. Common determinants such as poor diet's increasing the risk of both caries and obesity indicated a potential link between those diseases. This association has been suggested in 

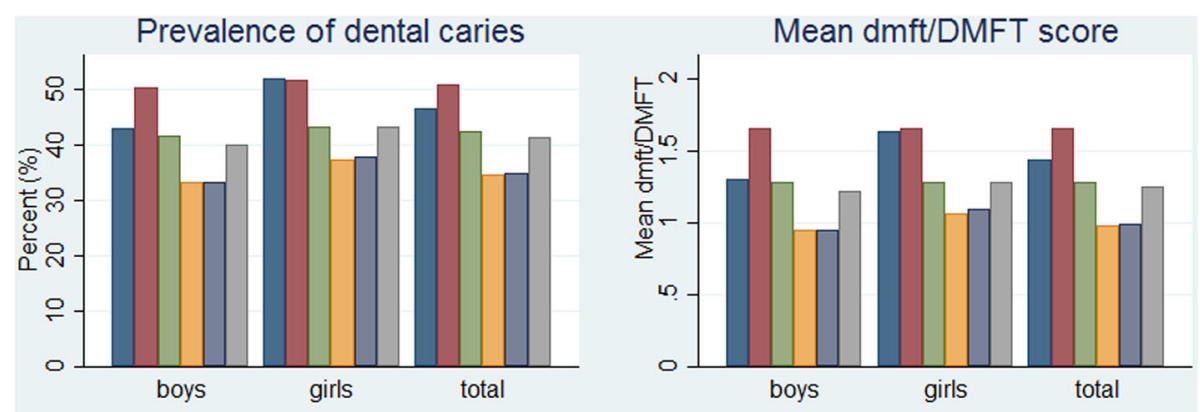

Caries fitting rates
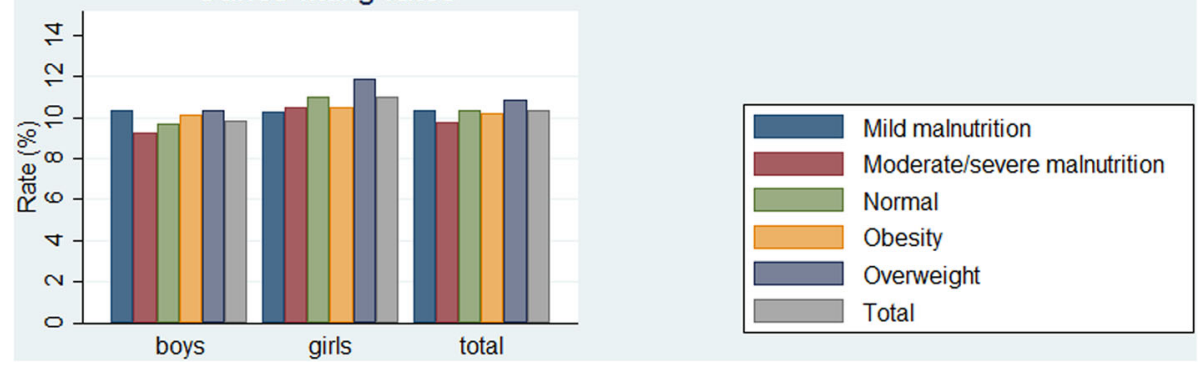

Fig. 2 Dental caries status in each BMI groups based on Chinese criteria

some studies [35-37], which reported that students with higher BMI were less likely to be caries free.

Here, we found that students in the lower BMI categories had higher risk of experiencing caries in both girls and boys. Similar results have been reported based on data from large surveys in Guangzhou [38] and the United States [39]. Liang et al. have demonstrated that overweight and obese children had lower odds for primary dental caries after adjusting for age and sex in a cross-sectional study in Guangzhou city [38]. Also, according to data from the National Health And Nutrition Examination Survey III in the United States [39], being overweight may be related to decreased rates of caries among children aged 2 to 18 years. However, a separate study (although with a smaller sample size of 835 participants) found no significant relationship between BMI and caries [13]. The significant disagreement among studies may be attributed to differences in the target population and caries severity. Severe caries are usually followed by toothache, which may reduce children's ability and willingness to eat, and thereby reduce their food intake. In addition, methods of categorizing BMI were different in these studies [13, 39-42]. Some studies employed CDC centiles [39, 40], while others used cutoff values recommended by the International Obesity Task Force [13, 41] or WHO [42]. One study also used BMI as a continuous variable [13]. In our study, the threshold was recommended by the Group of China Obesity TaskForce [19].

Our study supported an inverse relationship between dental caries and BMI categories. One possible explanation is that because of the one child policy in China, children have become "little emperors" at home. Family members (parents and grandparents) have spent more money on food, and most of them still believed that higher food intake makes their children grow faster. At the same time, they paid more attention to their child's oral health status. As a result, children with high BMI might have low odds of caries experience. However, this hypothesis could not be tested in our study since the information on parents' knowledge and attitude to diet and oral health is not available, further study is required. Moreover, caries severity was not recorded in the present survey. It is possible that students with malnutrition were more likely to have severe caries compared with their peers. As a consequence of malnutrition, enamel hypoplasia, salivary glandular hypofunction, and saliva compositional changes [43] might be potential sequelae linked to malnutrition and caries. In return, severe dental caries might result in a reduced food intake and thereby malnutrition, as mentioned above. Further studies with a longitudinal study design and comprehensive collections of socioeconomic backgrounds would be helpful in understanding the casual relationship.

To the best of our knowledge, this is the first large population-based survey in Shenzhen. The spatial and school-related disparities in childhood oral health found in this study could be the basis for policy implementation in the future. However, some limitations also exist in this study. First, we did not collect the information on dietary habits and family socioeconomic 
status, which may bias the observed association between oral health indicators and overweight/obesity, although it should not affect the accuracy of findings regarding dental caries status. Second, considering that the sample included all the school-aged students at school and senior high school is not covered in compulsory education, more efforts are required to assess whether these findings children who chose to leave school after junior high school. Moreover, no causal association could be summarized as with other crosssectional studies, further longitudinal studies and randomized controlled trials need to be conducted.

\section{Conclusion}

We found a high prevalence of primary teeth caries, low caries restoration rates, and regional disparities in school children in Shenzhen. Children who were overweight or obese had a lower caries rate than their peers in the malnutrition groups. Our results provide valuable information for implementing measures to improve the dental health of school children. Further studies are required to identify more factors associated with oral health problems.

\section{Abbreviations}

ANOVA: Analysis of variance; BMI: Body mass index; CDC: Center for disease control and prevention; CPI: Community periodontal index; DMFT: Decayed, missing, and filled teeth index for permanent teeth; dmft: Decayed, missing, and filled teeth index for primary teeth; GDP: Gross domestic product; WHO: World Health Organization

\section{Acknowledgements}

We would like to express my gratitude to Shenzhen Center for Disease Control and Prevention, which provided most of the data and gave us the opportunity to do this research. We also owe our sincere gratitude to all the hospitals that carried out dental and physical examinations and the schools involved in the census who coordinated with us. Last my thanks go to Dr. Yu Wu who helped a great deal when I was doing data analysis.

\section{Authors' contributions}

CYH and LY designed this study, analyzed the data, made maps and figures, and wrote the paper. CDY and WY collected and reorganized the data. WY did the data statistics and analysis. All authors have read and approved the manuscript.

\section{Funding}

This study was supported in part by Sanming Project of Medicine in Shenzhen (Grant No.SZSM201511007) and Postdoctoral Science Foundation of China (Grant No.2019 M653084). The funders have not influenced the research in any means and the research has been carried out independently.

\section{Availability of data and materials}

The data sets generated and analyzed during the current study are not publicly available because these data are stored in a government system, but are available from the corresponding author on reasonable request.

\section{Ethics approval and consent to participate}

This study used secondary data, and information that can identify specific individuals (including children under 16) was not included. Ethics approval and consent to participate are not applicable.

\section{Consent for publication}

Not Applicable.

\section{Competing interests}

The authors declare that they have no competing interests.

\section{Author details}

${ }^{1}$ Wuhan University, School of Stomatology, Wuhan, China. ${ }^{2}$ Shenzhen Center for Disease Control and Prevention, Shenzhen, China.

Received: 21 June 2019 Accepted: 7 November 2019

Published online: 04 December 2019

\section{References}

1. Selwitz RH, Ismail Al, Pitts NB. Dental caries. Lancet. 2007;369(9555):51-9.

2. Du MQ, et al. Dental caries status and its associated factors among 3- to 5year-old children in China: a National Survey. Chin J Dent Res. 2018;21(3): 167-79.

3. Quan JK, et al. Permanent teeth caries status of 12- to 15-year-olds in China: findings from the 4th National Oral Health Survey. Chin J Dent Res. 2018; 21(3):181-93.

4. Fourth National Oral Health Epidemiologic Survey Report. 2017; Available from: http://www.nhfpc.gov.cn/jkj/s5879/201709/9b4d4a4ec1c5472382 Odbaedf97a6d26.shtml. [cited 2018 4.28]

5. Cao XH, et al. Study on the current situation of dental caries among primary and secondary school students in Chongqing. Chin J Public Health. 2010; 26(1):28-30.

6. Liu JH, et al. Association of dental caries in children with body mass index. Chinese J Stomatol. 2017:11(1):36-40.

7. Ding L. Prevalence of permanent teeth caries among primary and secondary school students in Suzhou in 2015. Chinese J Child Health Care. 2015;25(6):621-4.

8. Petersen PE. The world Oral health report 2003: continuous improvement of oral health in the 21st century--the approach of the WHO global Oral health Programme. Community Dent Oral Epidemiol. 2003;31(Suppl 1):3-23.

9. Diet, nutrition and the prevention of chronic diseases. World Health Organ Tech Rep Ser. 2003:916

10. Ogden $\mathrm{CL}$, et al. Prevalence of obesity and trends in body mass index among US children and adolescents, 1999-2010. JAMA. 2012;307(5):483-90.

11. Hooley $\mathrm{M}$, et al. Body mass index and dental caries in children and adolescents: a systematic review of literature published 2004 to 2011. Syst Rev. 2012;1:57.

12. Marshall TA, et al. Dental caries and childhood obesity: roles of diet and socioeconomic status. Community Dent Oral Epidemiol. 2007:35(6):449-58.

13. Tramini $P$, et al. Association between caries experience and body mass index in 12-year-old French children. Caries Res. 2009;43(6):468-73.

14. Cinar AB, Murtomaa H. Interrelation between obesity, oral health and lifestyle factors among Turkish school children. Clin Oral Investig. 2011;15(2): 177-84.

15. Sanchez-Perez L, Irigoyen ME, Zepeda M. Dental caries, tooth eruption timing and obesity: a longitudinal study in a group of Mexican schoolchildren. Acta Odontol Scand. 2010;68(1):57-64.

16. Shenzhen Statistics Burea and NBS Survey Office in Shenzhen. Shenzhen Statistical Yearbook 2017. Vol. 12. Beijing: China Statistics Press; 2017. p. 4.

17. Ji CY. Prevalence of dental caries and caries degree among primary and secondary school students in China. Chinese J School Health. 2008;29(2): $114-7$.

18. Ministry of Education of the People's Republic of China. National investigation on students' physical constitution and health status in 2014. Beijing: Minstry of Education; 2014.

19. Group of China Obesity Task Force. Body mass index reference norm for screening overweight and obesity in Chinese children and adolescents. Chinese J Epidemiol. 2004;25(2):97-102.

20. Qi XQ. Third National Oral Health Epidemiologic Survey Report. Beijing: People's Medcial Publishing House; 2008.

21. World Health Organization. World Health Organization: Oral health global indicators for 2000. Geneva: World Health Organization; 1988

22. Joshi $\mathrm{N}$, et al. Prevalence, severity and related factors of dental caries in school going children of Vadodara city - an epidemiological study. J Int Oral Health. 2013:5(4):35-9.

23. Prasai Dixit $L$, et al. Dental caries prevalence, oral health knowledge and practice among indigenous Chepang school children of Nepal. BMC Oral Health. 2013;13:20 
24. Petersen PE, et al. The global burden of oral diseases and risks to oral health. Bull World Health Organ. 2005;83(9):661-9.

25. Japan Society of School Health. Movements towards School Health. Tokyo: Japan Society of School Health; 2003

26. Jokovic A, Locker D, Guyatt $G$. What do children's global ratings of oral health and well-being measure? Community Dent Oral Epidemiol. 2005; 33(3):205-11.

27. Zhang ZX. Children's dental caries. Adolesc Health. 2016;24:40-1.

28. Lopez R, Baelum V. Gender differences in tooth loss among Chilean adolescents: socio-economic and behavioral correlates. Acta Odontol Scand. 2006;64(3):169-76.

29. Dong YH, Ruan Q, Liu XH. Prevalence of dental caries among primary and secondary school students in Guangxi province in 2010. Chinese J Child Health Care. 2014;22(11):1221-3.

30. Huang $X$, et al. Investigation and analysis of snack consumption of junior middle school students in Changning District, Shanghai. Health Educ Health Promot. 2019;14(3):232-4.

31. Baume LJ. Report on a dental survey among the school population of French Polynesia. Population surveyed and numbers of teeth present. Arch Oral Biol. 1968;13(7):787-802.

32. South Money. Ranks of GDP increase in Shenzhen: what are the numbers of GDP increase in different districts in 2017?; Available from: http://www.sohu. com/a/230272786_119746. [cited 2018 5.3]

33. Gerdin EW, et al. Dental caries and body mass index by socio-economic status in Swedish children. Community Dent Oral Epidemiol. 2008;36(5):459-65.

34. Ludwig DS, Peterson KE, Gortmaker SL. Relation between consumption of sugar-sweetened drinks and childhood obesity: a prospective, observational analysis. Lancet. 2001;357(9255):505-8.

35. Qadri G, et al. Overweight and dental caries: the association among German children. Int J Paediatr Dent. 2015;25(3):174-82.

36. Hayden C, et al. Obesity and dental caries in children: a systematic review and meta-analysis. Community Dent Oral Epidemiol. 2013;41(4):289-308.

37. Sadeghi M, Alizadeh F. Association between dental caries and body mass index-for-age among 6-11-year-old children in Isfahan in 2007. J Dent Res Dent Clin Dent Prospects. 2007;1(3):119-24.

38. Liang JJ, et al. Dental caries is negatively correlated with body mass index among 7-9 years old children in Guangzhou, China. BMC Public Health. 2016;16:638.

39. Kopycka-Kedzierawski DT, et al. Caries status and overweight in 2- to 18year-old US children: findings from national surveys. Community Dent Oral Epidemiol. 2008;36(2):157-67.

40. Macek MD, Mitola DJ. Exploring the association between overweight and dental caries among US children. Pediatr Dent. 2006;28(4):375-80.

41. Cole TJ, et al. Establishing a standard definition for child overweight and obesity worldwide: international survey. BMJ. 2000;320(7244):1240-3.

42. Oliveira LB, Sheiham A, Bonecker M. Exploring the association of dental caries with social factors and nutritional status in Brazilian preschool children. Eur J Oral Sci. 2008;116(1):37-43.

43. Reyes-Perez $\mathrm{E}$, et al. Effect of early childhood protein-energy malnutrition on permanent dentition dental caries. J Public Health Dent. 2014;74(3):181-7.

\section{Publisher's Note}

Springer Nature remains neutral with regard to jurisdictional claims in published maps and institutional affiliations.

Ready to submit your research? Choose BMC and benefit from:

- fast, convenient online submission

- thorough peer review by experienced researchers in your field

- rapid publication on acceptance

- support for research data, including large and complex data types

- gold Open Access which fosters wider collaboration and increased citations

- maximum visibility for your research: over $100 \mathrm{M}$ website views per year

At BMC, research is always in progress.

Learn more biomedcentral.com/submissions 